\title{
BMJ Open Effectiveness and safety of yoga to treat chronic and acute pain: a rapid review of systematic reviews
}

\author{
Roberta Crevelário de Melo (D) ,' Aline Ângela Victoria Ribeiro (D) ," \\ Cézar D Luquine Jr (D , ,' Maritsa Carla de Bortoli, ${ }^{1}$ Tereza Setsuko Toma, ${ }^{1}$ \\ Jorge Otávio Maia Barreto ${ }^{3}$
}

To cite: Crevelário de Melo R, Victoria Ribeiro AÂ, Luquine $\mathrm{Jr} \mathrm{CD}$, et al. Effectiveness and safety of yoga to treat chronic and acute pain: a rapid review of systematic reviews. BMJ Open 2021;11:e048536. doi:10.1136/ bmjopen-2020-048536

- Prepublication history and additional supplemental material for this paper are available online. To view these files, please visit the journal online (http://dx.doi.org/10.1136/ bmjopen-2020-048536)

Received 29 December 2020 Accepted 25 November 2021

Check for updates

(c) Author(s) (or their employer(s)) 2021. Re-use permitted under CC BY-NC. No commercial re-use. See rights and permissions. Published by BMJ.

${ }^{1}$ Center for Health Technologies SUS/SP, Instituto de Saúde,

Secretaria da Saude do Estado de Sao Paulo, Sao Paulo, Brazil ${ }^{2}$ Institute of Philosophy and Human Sciences, State University of Campinas, Campinas, Brazil

${ }^{3}$ Fundacao Oswaldo Cruz, Brasília, Brazil

Correspondence to Dr Jorge Otávio Maia Barreto; jorgeomaia@hotmail.com

\section{ABSTRACT}

Background Pain is a sensation of discomfort that affects a large part of the population. Yoga is indicated to treat various health conditions, including chronic and acute pain. Objective To evaluate the effectiveness and safety of yoga to treat acute or chronic pain in the adult and elderly population.

Study selection A rapid review was carried out, following a protocol established a priori. Searches were carried out in September 2019, in six databases, using PICOS and MeSH (Medical Subject Headings) and DeCS (Descritores em Ciências da Saúde) terms. Systematic reviews were included, and methodological quality was assessed using Assessing the Methodological Quality of Systematic Reviews. The results were presented in a narrative synthesis.

Findings Ten systematic reviews were selected. Two reviews were assessed as of high methodological quality, two as of low quality, and six of critically low quality. Results were favourable to yoga compared with usual daily care, particularly in low back and cervical pain cases. There was little evidence about the superiority of yoga compared with active interventions (exercises, pilates or complementary and complementary medicine). It was also less consistent in pain associated with fibromyalgia, osteoarthritis, rheumatoid arthritis, carpal tunnel and irritable bowel syndromes. There was an improvement in the quality of life and mood of the participants, especially for yoga compared with usual care, exercises and waiting list.

Conclusions Overall, the results were favourable to yoga compared with usual care in low back and cervical pain cases. The evidence is insufficient to assert yoga's benefits for other pain conditions, as well as its superiority over active interventions. The findings must be considered with caution, given their low methodological quality and the small samples in the primary studies reported in the included systematic reviews. Thus, more studies must be carried out to improve the reliability of the results.

\section{BACKGROUND}

Pain is a major biopsychosocial problem worldwide because it affects the quality of life of individuals and causes considerable economic impact. ${ }^{1}$ Pain is a of subjective nature and can be described as an 'unpleasant
Strengths and limitations of this study

- This research followed a validated methodological guideline.

- Only the selection done duplicated and independently. The data extraction and quality assessment were performed by one reviewer and verified by another.

- No analyses were performed on the overlap of primary studies of the included systematic reviews.

- The systematic reviews included had their methodological quality assessed with the Assessing the Methodological Quality of Systematic Reviews tool.

- This review report adhered to the Preferred Reporting Items for Systematic Reviews and MetaAnalyses recommendations.

sensory and emotional experience associated with, or resembling that associated with, actual or potential tissue damage'. ${ }^{2}$ Although there is still no consensus on the definition of pain, according to the International Association for the Study of Pain it can be classified as either acute (lasts from a few seconds to 30 days) or chronic (more than 3 months to several years).$^{3-5}$

In 2017, the USA, Germany, France, Italy, Spain, UK and Japan reported an estimated 119619121 cases of acute pain related to surgery, trauma or other disease conditions. ${ }^{6}$ In the USA, acute pain was reported by 41766 061 patients after surgery and by 34068366 patients with traumatic injury. Between the European countries studied, Germany and the UK registered the highest number of acute pain cases. ${ }^{6}$

Pain is frequent in elderly people. Among residents from long-term care facilities, $49 \%-83 \%$ report that they were regularly in pain. ${ }^{7}$ More than $63 \%$ of older patients seen in primary healthcare also complain about acute pain. These symptoms were responsible for $69 \%$ of the accounted disability in daily routine life activities. ${ }^{7}$ 
A systematic review (SR) showed that low-back pain is the most prevalent, affecting $51 \%-84 \%$ of the general population, followed by cervical pain $(15.4 \%-45.3 \%) .{ }^{1}$ Pain can become a chronic condition that impacts an estimated $10 \%-55 \%$ of the population worldwide..$^{8-10}$ Accordingly, pain episodes in Europe, for example, compromise up to $3.0 \%$ of gross domestic product, with an annual cost higher than cancer and many heart diseases. ${ }^{1}$

In this context, non-pharmacological therapies, such as yoga, have been indicated to manage acute or chronic pain. Yoga is an integrative mind-body practice of oriental origin that involves three main elements: body positions (asana), techniques for controlling and/or regulating breathing (pranayama), and meditation and/ or relaxation (samyama). ${ }^{11}$ Currently, there are several yoga types, which differ mainly due to variations in the intensity, difficulty and duration of the postures, in addition to variations in the meditation and breathing techniques. 'Hatha yoga' and 'integrative yoga' are the terms commonly used to refer to several types of yoga practice, including those most used in Western societies, such as Iyengar and Vinyasa yoga or Viniyoga. ${ }^{11}$ Such yoga types have been used for many purposes, like physical rehabilitation and comprehensive care for emotionally traumatised individuals. ${ }^{12}$

The number of people who practice yoga has been increasing in recent years in Western countries. For example, in the USA, a study reported that approximately 31 million adult Americans have already practised yoga for the prevention of diseases and back pain relief. ${ }^{13}$ In Brazil, a survey carried out by the Ministry of Health $(\mathrm{MoH})$ in 2004 showed that $14.6 \%$ of the municipalities and states offered yoga at that time, mainly in primary healthcare. ${ }^{14}$ Also, yoga was incorporated into the National Policy of Integrative and Complementary Practices in Health, ${ }^{14}$ which instituted the offer of traditional and complementary medicines in the Brazilian Unified Health System (SUS). ${ }^{15}$ The incorporation of yoga in the SUS is officially justified by possible cognitive, musculoskeletal, endocrine and respiratory benefits. ${ }^{15}{ }^{16}$ For that reason, the number of healthcare providers offering yoga sessions in the SUS increased from 565 in 2017 to 7732 in 2019, as well as the number of patients assisted (from 3870 to 43459 , respectively). ${ }^{17}$

\section{METHODS}

Rapid review of SRs carried out by demand of the Brazilian $\mathrm{MoH}$. Rapid reviews are appropriate to provide decision makers with the best available evidence in a short time. ${ }^{18} \mathrm{~A}$ research protocol was previously prepared, describing the eligibility criteria, articles selection, data extraction and methodological quality assessment (online supplemental file 1). This review adhered the Preferred Reporting Items for Systematic Reviews and Meta-Analyses (PRISMA) 2020 reporting guidelines. ${ }^{19}$

\section{Eligibility criteria}

The research question was developed following PICOS framework: $\mathrm{P}=$ adultsand elderly with acute or chronic pain; I=yoga; $\mathrm{C}=$ usual treatment, placebo, or no treatment; $\mathrm{O}=$ reduction or control of acute or chronic pain and adverse events; $\mathrm{S}=\mathrm{SRs}$, with or without meta-analysis. Searches and selection of studies were guided by the following question: What is the effectiveness and safety of yoga practice to treat acute or chronic pain in an adult population, compared with usual treatments, placebo, or no treatment, based on the evidence of SRs?

We searched by SRs of randomised controlled trials (RCT), quasi-RCT, observational studies or qualitative studies, with or without meta-analysis, published in English, Spanish and Portuguese, with no restriction to publication date. Overviews, scoping reviews, integrative reviews, synthesis of evidence for policies, health technology assessment studies, economic assessment studies and primary studies were excluded. Studies that presented pain as a secondary outcome or did not present a clear report on the results were excluded.

\section{Search}

Searches were carried out on 27 September 2019, by two researchers, in indexed databases PubMed, Health Systems Evidence (HSE), Epistemonikos, VHL (Virtual Health Library) Regional Portal, Health Evidence (HE) and Embase. The search strategies combined keywords from the PICOS acronym, using MeSH (Medical Subject Headings) terms in Pubmed and DeCS (Descritores em Ciências da Saúde) terms in the VHL, adapting them to HSE, Epistemonikos, HE and Embase. The terms used were: "yoga”, "acute pain”, "chronic pain”, "ioga”, "dolor agudo", "dolor crónico", "dor aguda" and "dor crônica". The SR filter was used in three databases (PubMed, Epistemonikos, VHL Regional Portal) (online supplemental file 2).

\section{Study selection and data extraction}

The SRs retrieved were uploaded to Rayyan reference management web application. ${ }^{20}$ The screening process followed the steps of excluding duplicates and then reading titles and abstracts. The eligible articles were read in full. Those that did not meet the objectives of this rapid review were excluded. Using an Excel spreadsheet, the following data were extracted from the included studies: authorship, publication year, aims, intervention, comparators, results, limitations, conflicts of interest and last year searched. Both the study selection and data extraction were carried out by two reviewers independently. Conflicts were resolved by a third reviewer.

\section{Quality assessment}

Two reviewers independently assessed the methodological quality of studies with the Assessing the Methodological Quality of Systematic Reviews (AMSTAR 2) tool. ${ }^{21}$ Assessment disagreements between reviewers were resolved through consensus. To classify the overall confidence in 
Identification of studies via databases and registers

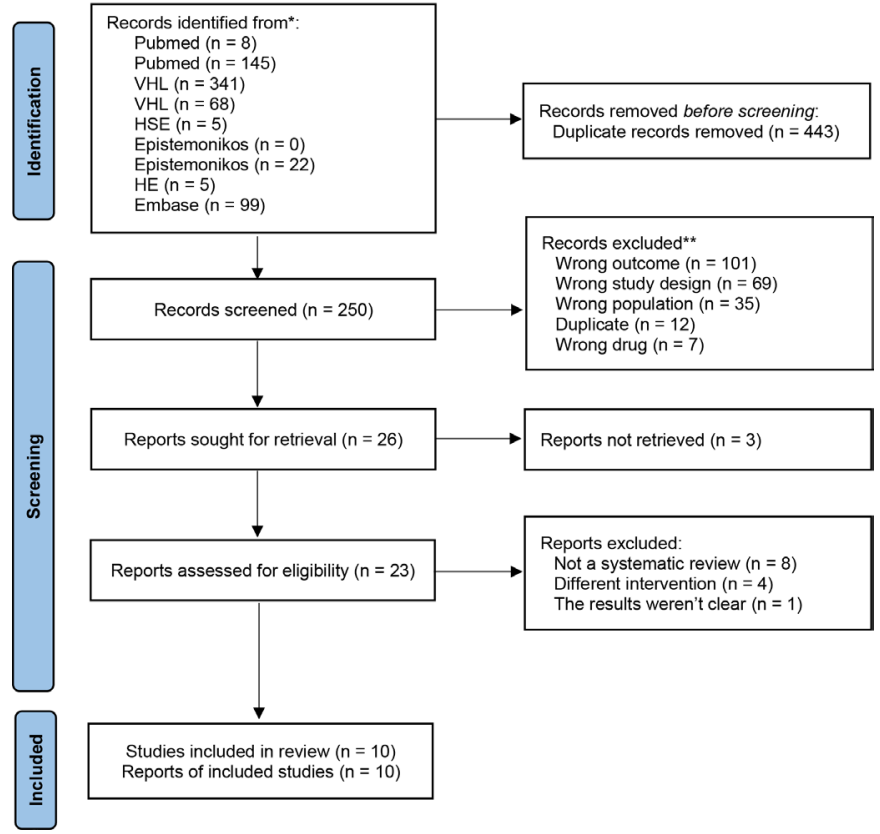

Figure 1 Study selection flow diagram, adapted from Preferred Reporting Items for Systematic Reviews and MetaAnalyses. $^{19}$

the results of the SRs, the 'critical domains' considered were the same suggest by the authors of AMSTAR 2 in their original article: study protocol (item 2); comprehensive search strategy (item 4); list of excluded studies with justification (item 7); adequate technique to assess the risk of bias in each study included in the review (item 9); appropriate methods for meta-analysis (item 11); risk of bias in each study when interpreting the results (item 13); and publication bias (item 15). Cohen's kappa statistic was calculated to estimate each domain's interrater reliability (IRR).

\section{Synthesis of results}

Results were analysed based on the effect size measures informed by the SRs (MD: means difference; RR: risk ratio; SMD: standardised means difference; $95 \% \mathrm{CI} ; \mathrm{I}^{2}$ : heterogeneity measure). A narrative synthesis of the results was prepared for each outcome about benefits and adverse events.

\section{Patient and public involvement}

No patients or public participated in any stage of this review. Results were presented to decision makers.

\section{RESULTS}

\section{Selection}

The PRISMA flow diagram shows the selection process (figure 1). Searches yielded 693 references, of which 250 remained for screening of titles and abstracts after duplicates were removed. Records were excluded after screening because they were a duplicate $(4.8 \%$ out of
$250)$, full-text not available $(1,2 \%)$ or for not meeting at least one of the eligibility criteria: outcome $(40.4 \%)$, not an SR (27.6\%), population (14\%) or intervention $(2,8 \%)$. Twenty-three reviews were read in full to check eligibility and 13 were excluded for the following reasons: not an SR, ${ }^{22-29}$ not an yoga intervention ${ }^{30-33}$ or necessary data unavailable for extraction. ${ }^{34}$ Thus 10 SRs were included, ${ }^{12}$ 35-43 eight with meta-analysis (online supplemental file 3).

\section{STUDIES CHARACTERISTICS}

Primary studies included in the SRs were conducted in the USA (5), ${ }^{35-39}$ India (4), ${ }^{36-39}$ Sweden (3), 353839 Germany (2), ${ }^{36} 39$ China (2), ${ }^{38} 39$ Korea (2), ${ }^{38} 39$ England (2), ${ }^{37} 38$ Brazil (2), ${ }^{35} 38$ Spain (1) ${ }^{35}$ and Turkey (1). ${ }^{39}$ Five reviews did not present this information. ${ }^{1240-43}$

The studies included in the reviews analysed different types of yoga, the most frequent ones being yoga iyengar, ${ }^{12} 3738404243$ hatha yoga ${ }^{37-394243}$ and viniyoga, ${ }^{37} 38$ 40-43 yogic mind resonance technique, ${ }^{39}$ yoga of awareness, ${ }^{35} 43$ yoga-based special techniques ${ }^{37}$ yogic meditation $^{37}$ and two reviews did not specify a yoga type used. $^{12} 40$

Yoga was combined with home practice, ${ }^{35-38} 41-43$ daily mostly, educational resources (booklets, guides, newsletters) about yoga ${ }^{37} 38{ }^{41-43}$ or pain, ${ }^{37}$ CDs (Compact Disc) or DVDs (Digital Versatile Disc), ${ }^{35} 384243$ physiotherapy, ${ }^{36}{ }^{39}$ relaxation, ${ }^{35} 40$ education, ${ }^{40}$ occupational therapy sessions ${ }^{37}$ and usual care. 37384142

The person responsible for the practice was mentioned to be an experienced yoga teacher, ${ }^{36} 374243$ but this information was not available for the majority of SRs included. $^{12} 3536$ 39-41

The duration of sessions ranged from $15 \mathrm{~min}^{41}$ to 3 hours $^{12}$ and frequency varied from one ${ }^{12}$ to seven times ${ }^{43}$ per week. The follow-up of participants continued for the minimum of $1^{42}$ and maximum of $24^{38}$ weeks.

Comparisons were made to usual care, ${ }^{1235-374042}$ educational interventions, ${ }^{12} 3738$ 41-43 ${ }^{\text {standard medical care }}{ }^{42}$; exercises, ${ }^{12}$ 37-39 41 and delayed treatment. ${ }^{35}$ Yoga interventions were also compared with waiting list controls, mostly unspecified, ${ }^{123740}$ but in one case there was a subsequent offer of intervention or treatment at some point or at the end of the study. ${ }^{38}$ Other integrative practices such as Tai-chi or pilates ${ }^{39}$ or no intervention ${ }^{12} 40$ were compared as well.

SRs described results on the following outcomes: pain, functional capacity, psychosocial outcomes, quality of life, specific back deficiency, overall clinical improvement and adverse events. The effectiveness of yoga was assessed in reducing low-back pain ${ }^{12} 384142$; cervical pain ${ }^{36}$ 39; pain associated with fibromyalgia ${ }^{35}$; pain associated with irritable bowel syndrome ${ }^{12}$; pain associated with carpal tunnel syndrome $^{12}$; pain caused by musculoskeletal conditions ${ }^{43}$; and chronic non-malignant pain. ${ }^{40}$

Pain after yoga was measured using the following scales and questionnaires: Visual Analogue 


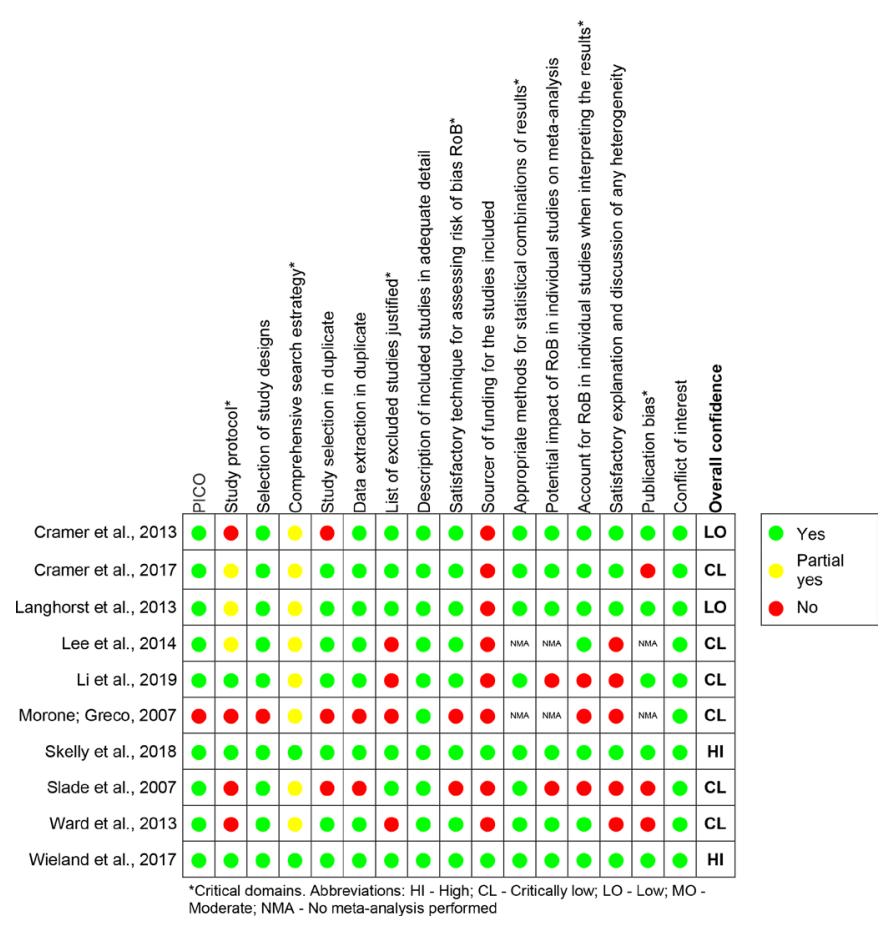

Figure 2 Summary of quality using Assessing the Methodological Quality of Systematic Reviews.

Scale $^{1235-404243}$; Numeric Rating Scale ${ }^{12} 38394243$; Aberdeen Back Pain Scale ${ }^{12} 373842$; McGill Pain Questionnaire and variations ${ }^{12} 383942$; Pain Bothersomeness Scales ${ }^{124243}$; Pain Analogue Scale ${ }^{36}$; Pain Diary ${ }^{12}$; Joint tenderness and hand pain during activity ${ }^{40}$; Brief Pain Inventory ${ }^{38}$; Pain Disability Index ${ }^{38}$; Simple Descriptive Pain Intensity Scale $^{43}$; Neck Pain and Disability Scale ${ }^{39}$; Neck pain-related disability $^{36}$; Oswetry disability index pain ${ }^{12}{ }^{37}$; Northwick Park Questionnaire ${ }^{39}$; Pain and Disability Chronic Pain Grade Scale $^{39}$; Pressure Pain Threshold ${ }^{39}$; Pain and physical function Western Ontario and McMaster Universities $^{40}$; Symptom bothersomeness. ${ }^{40}$

\section{QUALITY ASSESSMENT}

Two SRs were of high methodological quality, ${ }^{37} 38$ two were assessed as low quality, ${ }^{35} 42$ and six of critically low quality. ${ }^{12} 36$ 39-41 43 Overall IRR before consensus was estimated from an average of Cohen's kappa $(\kappa)$ through AMSTAR 2 domains (mean $\kappa=0.59$ ). Figure 2 details the assessment of each AMSTAR 2 item.

\section{SYNTHESIS}

Yoga reduced low-back pain, ${ }^{12} 37384142$ cervical pain, ${ }^{36} 39$ pain associated with fibromyalgia, ${ }^{35}$ pain associated with irritable bowel syndrome, ${ }^{12}$ pain associated with carpal tunnel syndrome, ${ }^{12}$ pain caused by musculoskeletal conditions $^{43}$ and chronic non-malignant pain. ${ }^{40}$

\section{Low-back pain}

Six SRs evaluated the effectiveness of yoga in reducing low-back pain in patients with chronic pain ${ }^{12} 37384142$ or low-back pain in general. ${ }^{43}$ Comparisons were made to usual care, exercise, educational interventions, attention control and waiting list individuals.

Compared with usual care, medical care or education, ${ }^{42}$ yoga decreased low-back pain in the short term, that is, right after the intervention and 12 weeks after randomisation, (6 RCT, 584 patients, $\mathrm{SMD}=-0.48$; $95 \%$ CI -0.65 to $\left.-0.31 ; \mathrm{I}^{2}=0 \%\right)$ and in the long term a year after randomisation (6 RCT, 564 patients, $\mathrm{SMD}=-0.33 ; 95 \% \mathrm{CI}-0.59$ to $\left.-0.07 ; \mathrm{I}^{2}=48 \%\right)$. In comparison to attention control or waiting list, ${ }^{38}$ yoga was associated with moderately larger effects on short term, 1 to $<6$ months (5 RCT, 770 patients, pooled difference $=-1.10 ; 95 \%$ CI -1.77 to -0.42 ; $\mathrm{I}^{2}=74 \%$ ) and intermediate term, $\geq 6$ to $<12$ months (2 RCT, 271 patients, pooled difference $=-1.17 ; 95 \%$ CI -1.91 to $-4.44 ; \mathrm{I}^{2}=26 \%$ ). Also, yoga showed a intermediate-term effect of large magnitude (26-32 weeks) for non-specific chronic low-back pain control (2 trials, 88 participants, pooled $\mathrm{SMD}=0.92 ; 95 \%$ CI 0.47 to 1.37 ; heterogeneity not reported) compared with education through a self-care book without physical exercises. ${ }^{41}$ Moreover, yoga showed a moderate overall effect on reducing low-back pain (4 RCT, number of participants not informed, $\mathrm{SMD}=-0.61$; $95 \%$ CI -0.97 to $-0.26 ; \mathrm{I}^{2}=63 \%$ ) compared with passive interventions (usual daily care, waiting list, educational or social environment). ${ }^{43}$

Compared with no exercise, ${ }^{37}$ the results favoured yoga as way of reducing low-back pain in the follow-up of 4-6 weeks ( 2 RCT, 40 participants, $\mathrm{MD}=-10.83$; 95\% CI -20.85 to $-0.81 ; \mathrm{I}^{2}=0 \%$ ), $3-4$ months (5 RCT, 458 participants, $\mathrm{MD}=-4.55 ; 95 \% \mathrm{CI}-7.04$ to $\left.-2.06 ; \mathrm{I}^{2}=0 \%\right)$, and at 6 months (4 RCT, 414 participants, $\mathrm{MD}=-7.81$; 95\% CI -13.37 to $-2.25 ; \mathrm{I}^{2}=64 \%$ ). At 12 months, the differences were not statistically significant. These results were moderate confidence at 6 months, but low to very low confidence in other follow-up points.

Furthermore, results favoured yoga compared with the practice of exercises after 1 week intensive practice (1 RCT, 80 participants, $\mathrm{MD}=-14.50$; $95 \%$ CI -22.92 to -6.08 ; heterogeneity not applicable), 4 weeks (1 RCT, 54 participants, $\mathrm{MD}=-15.00 ; 95 \% \mathrm{CI}-19.90$ to -10.10 ; heterogeneity not applicable) and 7 months (1 RCT, 54 participants, $\mathrm{MD}=-20.40,95 \%$ CI -25.48 to -15.32 ; heterogeneity not applicable). However, these results analyse single studies with small samples. ${ }^{37}$ A second SR that compared yoga to physical exercise $^{38}$ found heterogeneous results not statistically significant.

A review without meta-analysis ${ }^{12}$ reported that yoga effectively reduced chronic low-back pain. However, two studies included in the review pointed out that there was no evidence of pain improvement.

\section{Low-back pain-related disability}

Yoga practice compared with usual daily care, medical care or education ${ }^{42}$ contributed to reduce specific disability associated with low-back pain in the short term, right after the intervention and 12 weeks after randomisation (8 RCT, 689 patients, SMD $=-0.59 ; 95 \%$ CI -0.87 
to $\left.-0.30 ; \mathrm{I}^{2}=59 \%\right)$ and long term a year after randomisation ( 5 RCT, 574 patients, $\mathrm{SMD}=-0.35 ; 95 \% \mathrm{CI}-0.55$ to $-0.15 ; \mathrm{I}^{2}=20 \%$ ). Also, yoga showed a moderate effect on improving functionality in patients with low-back pain compared with reading self-care books and exercises (8 RCT, number of participants not informed, $\mathrm{SMD}=-0.64$; $95 \%$ CI -0.89 to $\left.-0.39 ; \mathrm{I}^{2}=62 \%\right){ }^{43}$

In the same way, results favoured yoga when it was compared with no exercise. ${ }^{37}$ Improvement was observed in the follow-ups of 4-6weeks (5 RCT, 256 participants, $\mathrm{SMD}=-0.45 ; 95 \% \mathrm{CI}-0.71$ to $\left.-0.19 ; \mathrm{I}^{2}=0 \%\right), 3-4$ months $(7$ RCT, 667 participants, $\mathrm{SMD}=-0.40 ; 95 \%$ CI -0.66 to -0.14 ; $\mathrm{I}^{2}=54 \%$ ), 6 months (6 RCT, 630 participants, SMD $=-0.44$; $95 \% \mathrm{CI}-0.66$ to $-0.22 ; \mathrm{I}^{2}=34 \%$ ) and 12 months (2 RCT, 365 participants, $\mathrm{SMD}=-0.26 ; 95 \%$ CI -0.46 to -0.05 ; $\left.\mathrm{I}^{2}=0 \%\right)$. The evidence, however, was considered of moderate confidence at 6 months and of low confidence for the other periods. When yoga was compared with exercise no differences were observed in specific back functionality. ${ }^{37}$

\section{Low-back pain clinical improvement}

Concerning clinical improvement, yoga did better compared with no exercise after 4-6weeks (2 RCT, 141 participants, RR=2.62; $95 \%$ CI 1.22 to $5.67 ; \mathrm{I}^{2}=0 \%$ ), at 3 months (3 RCT, 168 participants, RR=3.18; 95\% CI 1.86 to $5.44 ; \mathrm{I}^{2}=0 \%$ ), and at 6 months ( 1 RCT, 128 participants, $\mathrm{RR}=2.53 ; 95 \%$ CI 1.36 to 4.71 ; heterogeneity measure not applicable) ${ }^{37}$ However, such evidence was considered of low confidence. Otherwise, yoga compared with exercise showed no statistically significant difference in clinical improvement. ${ }^{37}$

\section{Cervical pain}

A meta-analysis ${ }^{36}$ showed better short-term (not specified) effects of yoga on the intensity of neck pain compared with usual care (3 RCT, 182 participants, $\mathrm{SMD}=-1.28$; $95 \% \mathrm{CI}-1.81$ to $\left.-0.75 ; \mathrm{I}^{2}=62 \%\right)$. Yoga also showed better results than exercises ( 8 RCT and 1 q-RCT, 488 participants, $\mathrm{SMD}=-1.26 ; 95 \% \mathrm{CI}-1.83$ to $\left.-0.68 ; \mathrm{I}^{2}=87 \%\right)$. However, authors found no statistically significant differences comparing yoga to pilates or complementary and complementary medicine. ${ }^{39}$

\section{Cervical pain-related disability}

Compared with usual care, yoga showed better short-term (not specified) effects on cervical pain-related disability (3 RCT, 182 participants, $\mathrm{SMD}=-0.97 ; 95 \%$ CI -1.44 to -0.50 ; $\left.\mathrm{I}^{2}=55 \%\right) \cdot{ }^{36}$ In comparison to exercise, ${ }^{39}$ yoga was superior in reducing disability (6 RCT and 1 q-RCT, 363 participants, $\mathrm{SMD}=-0.97,95 \% \mathrm{CI}-1.55$ to $-0.38 ; \mathrm{I}^{2}=82 \%$ ), but there was no significant difference when compared with pilates or complementary and complementary medicine.

\section{Pain associated with fibromyalgia syndrome}

Practicing yoga reduced the pain associated with fibromyalgia syndrome in the short term (not specified) compared with late or usual treatment (2 RCT, 88 patients, $\mathrm{SMD}=-0.54 ; 95 \%$ CI -0.96 to $\left.-0.11 ; \mathrm{I}^{2}=0\right){ }^{35}$
Pain associated with osteoarthritis and rheumatoid arthritis, and carpal tunnel and irritable bowel syndromes

Yoga significantly improved hand pain associated with osteoarthritis (after 8weeks) and rheumatoid arthritis (after 40 days) compared with passive interventions. ${ }^{43}$ One SR included one study that showed improvement in pain and physical function assessments in osteoarthritis. Also, a second study found improvement in joint sensitivity and hand pain during yoga. ${ }^{40}$

An SR considered yoga and standard care (eg, wearing a wrist splint) equally beneficial to carpal tunnel syndrome pain based in one primary study. ${ }^{12}$ Another study in the same review reported that yoga was not an effective treatment option for irritable bowel syndrome pain. ${ }^{12}$

\section{Quality of life and mood}

Compared with usual care, yoga improved quality of life (2 RCT, 128 participants, $\mathrm{SMD}=0.57 ; 95 \%$ CI 0.17 to 0.97 ; $\left.\mathrm{I}^{2}=20 \%\right)$ and $\operatorname{mood}(2 \mathrm{RCT}, 128$ participants, $\mathrm{SMD}=-1.02$; $95 \% \mathrm{CI}-1.38$ to $-0.65 ; \mathrm{I}^{2}=0 \%$ ) in patients with cervical pain. ${ }^{36}$

Yoga compared with delayed treatment control in patients with fibromyalgia improved the quality of life (1 RCT, 53 participants, SMD $=-0.71,95 \%$ CI -1.27 to -0.15 , heterogeneity measure not applicable) and depression (1 RCT, 53 participants, $\mathrm{SMD}=-0.84,95 \%$ CI -1.41 to -0.28 , heterogeneity measure not applicable) at the end of the treatment. ${ }^{35}$

Yoga compared with non-exercise controls improved the physical quality of life after 6 months (1 RCT, 259 participants, $\mathrm{SMD}=0.26,95 \% \mathrm{CI} 0.01$ to 0.50 , heterogeneity measure not applicable), and depression decrease 4-6weeks after the intervention (1 RCT, 16 participants, $\mathrm{SMD}=-1.23,95 \% \mathrm{CI}-2.39$ to -0.06 , heterogeneity measure not applicable). The intervention also decreased depression in participants with chronic low-back pain after 6 months (1 RCT, 90 participants, SMD $=-0.47,95 \%$ CI -0.89 to -0.05 , heterogeneity measure not applicable) and 12 months ( 1 RCT, 90 participants, SMD $=-0.50,95 \%$ CI -0.92 to -0.08 , heterogeneity measure not applicable). ${ }^{37}$

Yoga compared with exercises improved quality of life (3 RCT, 434 participants, MD=3.46, 95\% CI 95\% 0.75 to $6.16, \mathrm{I}^{2}=61 \%$ ) and $\operatorname{mood}(4 \mathrm{RCT}, 351$ participants, $\mathrm{SMD}=0.61,95 \%$ CI 0.95 to $\left.0.27, \mathrm{I}^{2}=58 \%\right)$ in patients with chronic cervical pain. ${ }^{39}$ Yoga compared with exercise controls showed an effect in the physical quality of life of chronic low-back pain patients after 4 weeks (1 RCT, 54 participants, $\mathrm{SMD}=1.68,95 \%$ CI 1.06 to 2.31 , heterogeneity measure not applicable) and after 7 months (1 RCT, 54 participants, SMD 1.34, 95\% CI 0.75 to 1.94, heterogeneity measure not applicable). Yoga compared with exercise controls improved the mental quality of life after 4 weeks ( 1 RCT, 54 participants, $\mathrm{SMD}=0.79$, $95 \%$ CI 0.24 to 1.35 , heterogeneity measure not applicable) and after 7 months (1 RCT, 54 participants, $\mathrm{SMD}=1.33,95 \%$ CI 0.74 to 1.92 , heterogeneity measure not applicable). ${ }^{37}$ 


\section{Safety of yoga}

Seven SRs reported information about adverse events associated with yoga. Three showed that yoga was not associated with serious adverse events. ${ }^{35} 3642$ Nevertheless, yoga was associated with increased low-back pain in some patients and an unspecified severe adverse event, ${ }^{43}$ increased pain and herniated disc, ${ }^{12}$ and a case of cellulitis. ${ }^{38}$ Moreover, one SR found no differences between reports of adverse events comparing yoga to other exercises. ${ }^{37}$

\section{DISCUSSION}

Overall, SRs favoured yoga compared with usual care, particularly in low back ${ }^{42}$ and cervical ${ }^{36}$ pain. Alternatively, there is little evidence about the superiority of yoga compared with active interventions. ${ }^{37-39}$ Furthermore, the effectiveness of yoga was unclear for other conditions identified, such as pain associated with fibromyalgia, ${ }^{35}$ osteoarthritis, ${ }^{40} 43$ rheumatoid arthritis, ${ }^{40}$ carpal tunnel and irritable bowel syndromes. ${ }^{12}$ Considering the seven SRs that provided information about safety, ${ }^{12}$ 35-38 4243 three reported no adverse events and another three found no severe adverse events (cellulitis, ${ }^{38}$ herniated $\operatorname{disc}^{12}$ and unspecified severe adverse event) ${ }^{43}$ related to the intervention. Hence, the results of this rapid review suggest yoga can benefit health without harm.

In Brazil, the $\mathrm{MoH}$ has regulated integrative and complementary practices in the Unified Health System to promote health and quality of life through less invasive techniques.

A Brazilian study highlighted the positive effects of integrative and complementary practices such as yoga in primary healthcare. It indicated that such interventions are easy to implement, mainly because they grant autonomy and allow patients to cope with illness. However, it should be noted that the lack of infrastructure and poor communication with other health services may damage its effectiveness. ${ }^{44}$

\section{Comparison with other evidence}

Similarly to what this rapid review found, the overview by Fishbein and Saper ${ }^{11}$ points out that yoga is not related to high rates of serious adverse events. However, yoga should be performed according to each individual's health condition. The study also indicates that the small sample size and lack of appropriate methods conducting primary studies diminish the quality of the evidence about the benefits of yoga.

Furthermore, a second overview targeting adults with acute and chronic health problems showed the benefits of yoga to pain control. The findings also stress the lack of robustness of the studies, which compromises the evidence. $^{45}$

\section{Strengths and limitations}

This rapid review was carried out in 45 days, simplifying steps from a traditional SR. Nonetheless, the shortcuts employed have followed a validated methodological guideline and the risks of them leading to inaccurate findings were considered.

The lack of information about the quality of primary studies included in the SRs decreased confidence in their results. It is noteworthy that even SRs themselves lack methodological rigour, since most of them were rated low or critically low overall confidence. The results are also based on primary studies with small samples, significant heterogeneity regarding the design of interventions, and considerable risk of bias. Hence, it is difficult to evaluate the effectiveness of yoga, and many uncertainties remain concerning its benefit.

\section{CONCLUSION}

Yoga can be an effective and safe practice to control chronic and acute pain, primarily in patients with low back or chronic cervical pain. Otherwise, the results were not very consistent for people with pain associated with osteoarthritis, rheumatoid arthritis, fibromyalgia, carpal tunnel and irritable bowel syndromes. Overviews of SRs highlighted the benefit of yoga for controlling acute and chronic pain, which corroborates the findings of this review. Therefore, more research is needed to increase the quality and strength of these results.

\section{Twitter Cézar D Luquine Jr @czrlqn}

Acknowledgements To the team of the National Coordination of Integrative and Complementary Practices of the Ministry of Health (CNPICS/DESF/SAPS/MS), for presenting the original demand for the production of this rapid review.

Contributors AÂVR and RCdM contributed to eligibility and extraction processes, article text development, research reports construction and final manuscript elaboration. CDLJ and MCdB contributed to manuscript revision. JOMB and TST coordinated the study. All authors contributed, revised and approved the final article. JOMB is the guarantor of the study.

Funding The Brazilian Ministry of Health commissioned this rapid review as part of the PRES008-FI0-18 project, developed by the 0swaldo Cruz Foundation (Fiocruz). This publication was also supported by a project funded by the Ministry of Health of Brazil (TED MS/SCTIE-Fiocruz \# 43/2016).

Competing interests This rapid review was commissioned and subsidized by the Ministry of Health, but the authors declare that the funding body did not interfere in the conduct of the review or the presentation of its results.

Patient consent for publication Not applicable.

Ethics approval This study does not involve human participants.

Provenance and peer review Not commissioned; externally peer reviewed.

Data availability statement All data relevant to the study are included in the article or uploaded as supplementary information. Not applicable.

Supplemental material This content has been supplied by the author(s). It has not been vetted by BMJ Publishing Group Limited (BMJ) and may not have been peer-reviewed. Any opinions or recommendations discussed are solely those of the author(s) and are not endorsed by BMJ. BMJ disclaims all liability and responsibility arising from any reliance placed on the content. Where the content includes any translated material, BMJ does not warrant the accuracy and reliability of the translations (including but not limited to local regulations, clinical guidelines, terminology, drug names and drug dosages), and is not responsible for any error and/or omissions arising from translation and adaptation or otherwise.

Open access This is an open access article distributed in accordance with the Creative Commons Attribution Non Commercial (CC BY-NC 4.0) license, which permits others to distribute, remix, adapt, build upon this work non-commercially, and license their derivative works on different terms, provided the original work is 
properly cited, appropriate credit is given, any changes made indicated, and the use is non-commercial. See: http://creativecommons.org/licenses/by-nc/4.0/.

\section{ORCID iDs}

Roberta Crevelário de Melo http://orcid.org/0000-0002-2698-9211

Aline Ângela Victoria Ribeiro http://orcid.org/0000-0003-4639-4060

Cézar D Luquine Jr http://orcid.org/0000-0002-5038-6808

\section{REFERENCES}

1 Henschke N, Kamper SJ, Maher CG. The epidemiology and economic consequences of pain. Mayo Clin Proc 2015;90:139-47.

2 International Association for Study of Pain (IASP). Pain, 2019. Available: https://www.iasp-pain.org/terminology?navltemNumber= 576\#Pain [Accessed 23 Oct 2020].

3 Harvey AM. Classification of chronic pain-descriptions of chronic pain syndromes and definitions of pain terms. Clin J Pain 1995;11:163.

4 Ministério da Saúde (Brasil). Protocolos clínicos E diretrizes terapêuticas: volume 3. Brasília: Ministério da Saúde, 2014: 3. 604. https://bvsms.saude.gov.br/bvs/publicacoes/protocolos_clinicos_ diretrizes_terapeuticas_v3.pdf

5 Raja SN, Carr DB, Cohen M, et al. The revised international association for the study of pain definition of pain: concepts, challenges, and compromises. Pain 2020;161:1976-82.

6 Research and Markets. Acute pain - epidemiology forecast to 2028, 2019: 77.

7 Mallon T, Ernst A, Brettschneider C, et al. Prevalence of pain and its associated factors among the oldest-olds in different care settings results of the AgeQualiDe study. BMC Fam Pract 2018;19:85.

8 Vasconcelos FH, Araujo GC. Prevalência de DOR crônica no Brasil: estudo descritivo. BrJP 2018;1:176-9.

9 Souza DFdaSde, Häfele V, Siqueira FV. Dor crônica E nível de atividade física em usuários das unidades básicas de saúde. Rev Bras Ativ Fís Saúde 2019;24:1-10.

10 Toscano JJO, Zefferino ACG, Felix JMC. Prevalência de DOR em servidores públicos: associação CoM comportamento sedentário $\mathrm{E}$ atividade física de lazer. Rev. dor 2016;17:106-10.

11 Fishbein DB, Saper RB. Overview of yoga. UptoDate, 2014.

12 Lee C, Crawford C, Schoomaker E, et al. Movement therapies for the self-management of chronic pain symptoms. Pain Med 2014;15 (Suppl 1):S40-53.

13 Cramer H, Ward L, Steel A, et al. Prevalence, patterns, and predictors of yoga use. Am J Prev Med 2016;50:230-5.

14 Ministério da Saúde. Política nacional de práticas integrativas e complementares no SUS: atitude de ampliação de acesso. 2nd edn. Saúde Brasília: Ministério da, 2015.

15 Ministério da Saúde (Brasil). Portaria 849, de 27 de março de 2017. Brasília: Ministério da Saúde, 2017.

16 Ministério da Saúde. TGlossário temático: práticas integrativas $E$ complementares em saúde. Brasília: Ministério da Saúde, 2018.

17 Ministério da Saúde. Relatório de monitoramento nacional das práticas integrativas E complementares em saúde NOS sistemas de informação em saúde. Brasília: Ministério da Saúde, 2020.

18 Tricco AC, Langlois EV. Straus se 143. rapid reviews to strengthen health policy and systems: a practical guide. Genebra: Organización Mundial de la Salud, 2018.

19 Page MJ, McKenzie JE, Bossuyt PM. The PRISMA 2020 statement: an updated guideline for reporting systematic reviews. BMJ 2021;372:71.

20 Ouzzani M, Hammady H, Fedorowicz Z, et al. Rayyan-a web and mobile APP for systematic reviews. Syst Rev 2016;5:210.

21 Shea BJ, Reeves BC, Wells G, et al. AMSTAR 2: a critical appraisal tool for systematic reviews that include randomised or nonrandomised studies of healthcare interventions, or both. $B M J$ 2017;358:j4008.

22 Anthony YL. Appraisal of nonpharmacological chronic pain management. Minneapolis: College of Health Sciences, Walden
University, 2017. https://scholarworks.waldenu.edu/cgi/viewcontent. cgi?article $=4689$ \& context=dissertations

23 Devan D. A review of current therapeutic practice for the management of chronic pain. South African Journal of Occupational Therapy 2014;44:48-50.

24 Hill C. Is yoga an effective treatment in the management of patients with chronic low back pain compared with other care modalities - a systematic review. J Complement Integr Med 2013;10:211-9 https:// www.degruyter.com/doi/

25 Miller S, Gaylord S, Buben A, et al. Literature review of research on chronic pain and yoga in military populations. Medicines 2017;4:64.

26 Kinser PA, Pauli J, Jallo N, et al. Physical activity and yoga-based approaches for pregnancy-related low back and pelvic pain. J Obstet Gynecol Neonatal Nurs 2017;46:334-46.

27 Chou R, Deyo R, Friedly J, et al. Nonpharmacologic therapies for low back pain: a systematic review for an American College of physicians clinical practice guideline. Ann Intern Med 2017;166:493-505.

28 Goode AP, Coeytaux RR, McDuffie J, et al. An evidence map of yoga for low back pain. Complement Ther Med 2016;25:170-7.

29 Kelley GA, Kelley KS. Meditative movement therapies and healthrelated quality-of-life in adults: a systematic review of meta-analyses. PLoS One 2015;10:e0129181.

30 Antunes PDC, Lagranha DM, Sousa MFde, et al. Revisão sistemática sobre práticas corporais $\mathrm{Na}$ perspectiva das práticas integrativas $\mathrm{E}$ complementares em saúde. Motrivivência 2018;30:227-47.

31 Brami C, Bao T, Deng G. Natural products and complementary therapies for chemotherapy-induced peripheral neuropathy: a systematic review. Crit Rev Oncol Hematol 2016;98:325-34.

32 Budhrani-Shani P, Berry DL, Arcari P, et al. Mind-body exercises for nurses with chronic low back pain: an evidence-based review. Nurs Res Pract 2016;2016:1-10.

33 Moura VL, Faurot KR, Gaylord SA, et al. Mind-body interventions for treatment of phantom limb pain in persons with amputation. Am J Phys Med Rehabil 2012;91:701-14.

34 Mira TAA, Buen MM, Borges MG, et al. Systematic review and metaanalysis of complementary treatments for women with symptomatic endometriosis. Int J Gynaecol Obstet 2018;143:2-9.

35 Langhorst J, Klose P, Dobos GJ, et al. Efficacy and safety of meditative movement therapies in fibromyalgia syndrome: a systematic review and meta-analysis of randomized controlled trials. Rheumatol Int 2013;33:193-207.

36 Cramer $\mathrm{H}$, Klose $\mathrm{P}$, Brinkhaus $\mathrm{B}$, et al. Effects of yoga on chronic neck pain: a systematic review and meta-analysis. Clin Rehabil 2017;31:1457-65.

37 Wieland LS, Skoetz N, Pilkington K, et al. Yoga treatment for chronic non-specific low back pain. Cochrane Database Syst Rev 2017;1:CD010671.

38 Skelly AC, Chou R, Dettori JR. Noninvasive nonpharmacological treatment for chronic pain: a systematic review. AHRQ 2018;209.

$39 \mathrm{Li} \mathrm{Y,} \mathrm{Li} \mathrm{S,} \mathrm{Jiang} \mathrm{J,} \mathrm{et} \mathrm{al.} \mathrm{Effects} \mathrm{of} \mathrm{yoga} \mathrm{on} \mathrm{patients} \mathrm{with} \mathrm{chronic}$ nonspecific neck pain: a PRISMA systematic review and metaanalysis. Medicine 2019;98:e14649.

40 Morone NE, Greco CM. Mind-body interventions for chronic pain in older adults: a structured review. Pain Med 2007;8:359-75.

41 Slade SC, Keating JL. Unloaded movement facilitation exercise compared to NO exercise or alternative therapy on outcomes for people with nonspecific chronic low back pain: a systematic review. J Manipulative Physiol Ther 2007;30:301-11.

42 Cramer $\mathrm{H}$, Lauche R, Haller $\mathrm{H}$, et al. A systematic review and metaanalysis of yoga for low back pain. Clin J Pain 2013;29:450-60.

43 Ward L, Stebbings S, Cherkin D, et al. Yoga for functional ability, pain and psychosocial outcomes in musculoskeletal conditions: a systematic review and meta-analysis. Musculoskeletal Care 2013;11:203-17.

44 Galvanese ATC, Barros NFde, d'Oliveira AFPL. Contribuições E desafios das práticas corporais $\mathrm{E}$ meditativas à promoção $\mathrm{dA}$ saúde Na rede pública de atenção primária do Município de São Paulo, Brasil. Cad Saude Publica 2017;33:e00122016.

45 McCall MC, Ward A, Roberts NW, et al. Overview of systematic reviews: yoga as a therapeutic intervention for adults with acute and chronic health conditions. Evid Based Complement Alternat Med 2013;2013:1-18. 